\title{
Critical Thinking Level of Bachelor Degree Nursing Students of Two Selected Universities in the Centre Region of Cameroon
}

\author{
Eyinga Paul Marius \\ Nurse, PhD Candidate in Curriculum and Teaching, Faculty of Education, \\ University of Buea, Buea, Cameroon
}

\begin{abstract}
Healthcare consumers' expectations are constantly changing and increasing in quality. So, nurses should be prepared to meet such health environment, whose complexity requires them to think critically. But there is little evidence that Cameroonian nurses of today think so. That is why the objective of this article was to determine the critical thinking level of bachelor degree students in nursing schools in the Centre Region of Cameroon. It was a survey design that implicated 229 students selected conveniently. Data were collected using a written test taken by students. Research ethical principles were rigorously observed. After administration of critical thinking tests, the analyses were done with SPSS version 19 . The population t-test was used. Findings revealed that, bachelor degree students' level of critical thinking (CT) is significantly low in both Adventist University $(\mathrm{t}=-4.71, \mathrm{p}=0.00)$ and in Catholic University $(\mathrm{t}=-$ $19.82, \mathrm{p}=0.00)$. The mean value of Adventist $(\mathrm{m}=8.10)$ was higher than the mean value of Catholic $(m=5.87)$. So, it was concluded that, the development of nurse student CT relies on a combination of variables; and that the use of a single particular teaching method is not sufficient to enhance nurse student CT competence. That is why it was recommended that, the Ministry of Higher Education, that of Public Health, Nurse councils and nursing schools urgently sit together to revise and harmonise the bachelor degree curriculum in nursing.
\end{abstract}

Keyword: Critical thinking, bachelor degree, nursing student

\section{INTRODUCTION}

The analysis of standards stated in different parts of the world as concerns nursing practice, reveals that they are all about critical thinking (CT) competence.
CTis the mental process by which one searches, obtains, evaluates, analyses synthesizes and conceptualizes information. This implies the nursing process (NP), which is a decision making approach in nursing. The term "nursing process" was first used by Lydia Hall in 1955, in a journal article (De La Cuesta, 1983). But, the word was not widely used until the late 1960s (Edelman \& Mandle, 2002). Couto and Teresinha (2012) maintained that the NP was first used in 1961 by Orlando and consisted of three steps: the client's behaviour, the nurse's reaction, and the nursing actions. But to Johnson (1959) and Wiedenbach (1963) the three steps of the NP were: assessment, planning, and evaluation. On the other hand, Yura and Walsh (1967) differed from them, maintaining that, the process has four stages: Assessment, Planning, Implementation, and Evaluation. In that line, Ashworth et al. (1987) later specified that in 1985, the World Health Organisation officially proposed a four-phase process (Assessment, Planning, Implementation, and Evaluation). But today, the NP is known as having five phases: Assessment, Diagnosis, Planning and outcome identification, Implementation and Evaluation. The NPis of great importance to nursing practice because it is used as a problem-solving activity to think about a plan of care as the basis for professional practice in everyday nursing practice. That is the reason why, Rush, Fergy and Weels (1996) postulated that the NP is an organised, systematic and deliberate approach to nursing which aim is to improve standards in nursing care. This means that, without effective CT or practical use of the NP, nurses cannot meet their expectations.

Apparently, CT is a fundamental dimension of nursing. So, a good nurse is that who shows mastery 
of it; that is mastery in carrying out the NP. But, in Cameroon, nurses seem not to meet those standards as yet. In fact, it can be said that, internationally, nursing education has evolved speedily since the introduction of bachelor nursing training in universities. For example, in Kenya, so many changes have happened in nursing education all through the last fifteen years(Chege, Mwaniki \&Abuya, 2013). Conversely, though Cameroon has also experienced the introduction of nursing curricula at under graduate and post graduate level sin several government and private universities since 2000, the situation appears to have not improved. For instance, in many hospitals, none of the nurses uses a nursing model to collect information from patients, as they are taught during their training (Eyinga, 2010). By so doing they cannot adequately assess patient health needs and expectations and analyse patient health situations in order to elaborate nursing diagnoses. When asked, for example, to list some nursing diagnoses, they mainly indicate medical diagnoses or terms that are neither medical diagnoses nor nursing diagnoses (Eyinga, 2010). Such a situation leads them to hardly ever identify appropriate nursing interventions.

An observation of nursing files, where it exists, shows that the few elements that usually appear in, are the biologic parameters, wound dressings and medicinal treatments. From this situation, it is evident that their interventions are not always adapted to the clinical condition of the patient and are limited to the application of medical prescriptions. As well, the researchers observed that nurses in Cameroon rarely document their interventions for traceability insurance. In some hospitals, there is no nursing file to document interventions, no nursing care plan, which is the information storing medium for Nurse CT. Instead, nurses use only a monitoring slip, where they fill biological parameters.

From the discussion above, the objective of this study was to determine the CT level of bachelor degree students in nursing schools in the Centre Region of Cameroon. The research question was the following: What is the level of CT of bachelor degree students in nursing schools in the Centre Region of Cameroon? The hypothesis was that the level of CT of bachelor degree students in nursing schools in the Centre Region of Cameroon is not significantly low.

\section{Methodology}

A cross-sectional survey was used in this investigation to collect information from nursing students within a single period (June 2017). The survey was thought convenient to determine the degree to which the planned bachelor degree curriculum in nursing schools in the Centre Region of Cameroon produces critical thinking nurses. To achieve this, a performance test was taken by students to assess their competence in the use of CT in nursing at the end of their programme and to determine student level of CT. To this effect, a valid and reliable tool for assessment of CT competence at the end of their programme appears to be fundamental. In fact, from the variety of approaches used to measure student CT, and from the limitations and merits of each approach, the researchers concluded that there was a need to develop valid and reliable assessment tool that best test the overall CT construct in nursing while providing efficiency in grading. Consequently, the researchers designed and validated a tool to measure nursing students' CT competence at the end of their bachelor degree programme in nursing. This instrument was used in the study due to its specificity in nursing. The instrument comprised six open-ended questions that required the students to collect data from a patient (presented as a case), to pose nursing diagnostics and justify them, to state nursing objectives from which he or she derived interventions and to organise them in a comprehensive plan of action (nursing care plan). These questions followed a vignette that presented the case.

Face validity of instrument was ensured by $10 \mathrm{Ph} . \mathrm{D}$. students in the Curriculum Studies and Teaching programme, Faculty of Education, University of Buea. They were presented with the CT test, and required to indicate how good they felt the test looked. They also helped correct grammatical and orthographic errors. Content validity, was ensured by 40 nursing content experts, holders of at least a master's degree in nursing. They were surveyed to collect content evidence on a tool to measure nursing students' CT competence. They were drawn from the Cameroon Nurses Association's list of members and from the graduates' list of the Catholic University of Central Africa between 2010 and 2016. They were required to examine the it ems on a proposed tool and to determine if the domains and it emspresented were representative of nurse CT. The Cronbach's alpha coefficient was 0.703 for competence domains and 0.845 for critical thinking questions. 
The Centre Region was selected because the majority of higher institutions of education and universities offering bachelor degree programmes in nursing in Cameroon are located in this region. Since it was not possible to get to all final-semester bachelor degree students, the researchers considered an accessible population of 294 student nurses, from which 229 voluntarily accepted to participate in the study and were selected. To Depelteau (2000), if the population is 300 , the sample must be at least 169 . So, a sample of 229 students is highly representative of the population of 294 .

The tests were administered after an appointment with students. They were allotted one hour to write the test, which was taken under true examination conditions, in the presence of one or two invigilators depending upon the size of the class. Two nurse educators assured the marking of the CT tests. Each CT script was marked twice (two markers). The scores retained were the average scores from the two markers who did not know each other. The first stayed in Douala and the second stayed in Yaoundé (256 kilometres from Douala).

The Population t-test was used to examine the research question. A description of sample characteristics was provided. A table was used to portray them. This statistical tool was thought suitable because the performance of nursing students was compared with a determined performance of the parent population and the variables involved were measured continuously. Research ethical principles of confidentiality and data protection, voluntary participation, and avoidance of harm, were rigorously observed.

\section{Findings}

The hypothesis of this research work was that the level of critical thinking of bachelor degree students in nursing schools in the Centre Region of Cameroon is not significantly low. To test this hypothesis, data were collected from bachelor degree students in two selected universities and analysed through the Population t-test.

Table 1: Population t-test analysis of bachelor degree student critical thinking in the bachelor curriculum in nursing schools in the Centre Region of Cameroon

\begin{tabular}{|l|l|l|l|l|l|l|}
\hline Test variable & $\mathbf{N}$ & Mean & SD & Reference & t-value & p-value \\
\hline CT Adventist & 71 & 8.10 & 3.55 & 10 & -4.78 & 0.00 \\
\hline CT Catholic & 158 & 5.87 & 2.61 & 10 & -19.82 & 0.00 \\
\hline
\end{tabular}

The results of the analysis of the data collected from the students' CT test showed that the p-values for CT for Adventist $(\mathrm{p}=0.00)$, and CT for Catholic $(\mathrm{p}=$ 0.00 ) were all lower than the significance level of 0.05 with 70 and 157 degrees of freedom respectively. From the results, the null hypothesis is therefore rejected. This means that CT levels of students from both schools were significantly low. Judging from the $\mathrm{t}$-values, the analysis revealed that the $\mathrm{t}$-value for the level of CT in Adventist is negative, hence, significantly low ( $\mathrm{t}-4.48)$. Also, the $\mathrm{t}$-value for the level of $\mathrm{CT}$ in Catholicis also negative, hence, significantly very low $(\mathrm{t}=-19.82)$.

\section{Discussion}

The study revealed that the level of CT of bachelor students in nursing schools in the Centre Region of Cameroon is significantly low, whereas CT is a key component of nursing practice. This result is similar to that of Akca and Selen (2015) who discovered a low CT level for nursing students in Turkey. They recommended the use of educational methods intended to increase students' CT level during nursing education. In that vein, Elliot (1996) posited that some particular teaching methods, if used appropriately can promote, attain and advance the acquisition of CT skills for students. Such teaching methods emphasized skills development rather than the transmission of information. Such methods are more student-centred and activity oriented. They include creative approaches to open nurses' mind and to widen and expand their ways of thinking and to help the process of problem-solving (Bittner \& Tobin, 1988). So, the responsibility to facilitate nursing students' development of CT skills lies in the hands of nurse educators. Kurfiss (1988) insisted that teaching methods that enhance students' CT abilities are, among others, small group activity, role-play, debate, case studies, simulations, problem-solving, writing assignments, questions that involve reasoning skills and ability to organise and articulate knowledge, dialoguing on complex problems. The researchers 
recommend that nurse educators use them as much as possible and appropriately. By this means, it can be expected that future Cameroonian nurses appropriately collect, analyse and interpret patient data to infer appropriate interventions that are to be implemented and evaluated. More importantly, Kak, Burkhalter and Cooper (2001) reported that low scores on competence assessments after training probably indicate that the training was ineffective, poorly designed, poorly presented or inappropriate.

The results of the current study contrast with that of Jun-Yan et al. (2015) who investigated and compared the clinical thinking ability of third-year, fourth-year, and fifth-year undergraduate student nurses in China. In that study, it was revealed that $71.1 \%$ of the students had a higher level of clinical thinking ability. A significant difference in the scores of the three groups was noted. They indicated that the frequency of academic activities and the frequency of department rounds were significantly correlated with clinical thinking ability. The authors concluded that attention must be paid to the influencing factors of clinical thinking ability of undergraduate student nurses. Amongst such factors are teaching, evaluation and testing methods used, teaching environment and availability of teaching materials. Therefore, nurse educators today should move from the use of traditional teaching methods such as lecture, to more active teaching methods such as problem-solving, case studies and simulation. In that way, nursing students can be expected to become critical thinkers by the end of their programmes.

In addition, the results of this study contradict the study of Kermansaravi, Navidianand Kaykhaei (2013) who discovered a significant difference between CT mean scores of junior, senior and graduate nursing students of Zahedan University of Medical Sciences. Their finding was that the CT level of senior students was superior to that of junior students and the CT level of graduate nursing students was inferior to that of the seniors. They concluded that though CT is central to nursing practice, during the training period, it has no significant development. This conclusion brings to light the fact that traditional approaches to teaching must evolve and be revised so that nursing students can develop their CT skills and become effective health professionals.

Furthermore, when Mahmoud and Mohamed (2017) investigated CT disposition among nurses working in
Public Hospitals in Port-Said Governorate, they evidenced that more than three-quarters of the nurses had an ambivalent disposition toward CT and most scores indicated a negative tendency towards truthseeking. These results are very similar to those of this study, which reveal that the level of CT of bachelor students in nursing schools in the Centre Region of Cameroon is significantly low. Mahmoud and Mohamed (2017) pointed up the upgrading of nurses' CT through educational programmes. The programmes should stress the use of more problembased learning, cooperative learning, discussion and other innovative and active teaching strategies. In fact, Kaddoura (2011) discovered that case-based learning promotes nursing students CT compared to didactic teaching. That is why the researchers highly recommend nurse educators to use active learning methods with their students.

\section{Conclusion}

A lot of effort must be made to promote nurse students' CT competence to permit nurses leave to the expectations of the demand of the complex health environment of today which required them higher order thinking. In that sense, educators are encouraged to use a combination of methods known to help develop student CT ability systematically, because the use of one single method seems to be ineffective to help students develop CT competence. Also, due to the significantly low level of student CT, which put patients' safety at stake, the Ministry of Higher Education, the Ministry of Public Health, the Nurse Councils, nurses' associations, and nursing schools are encouraged to urgently sit together to revise and harmonise bachelor degree curriculum in nursing in Cameroon.

\section{References}

1. Akca, S. O., \& Selen, F. (2015). Nursing Students' Critical Thinking Levels. The European Proceedings of Social \& Behavioural Sciences, 74-84.

https://www.futureacademy.org.uk/files/menu_ite ms/other/8ich.pdf

2. Ashworth, P., Bjor, A., Dechanoz, G., Delmotte, N., Farmer, E., Kordas, A. B., et al. (1987). People's needs for nursing care: a European study. A study of nursing care needs and of the planning, implementation and evaluation of care provided by nurses in two selected groups of people in the European Region. Copenhagen 
International Journal of Trend in Scientific Research and Development (IJTSRD) ISSN: 2456-6470

(DK): World Health Organization-Regional Office for Europe.

3. Bittner, N. P., \& Tobin, E. (1988). Critical Thinking: Strategies for Clinical Practice. Journal for Nurses in Professional Development, 14(6), 267-272.

4. Chege, M. N., Mwaniki, P. K., \& Abuya, T. O. (2013). Evaluation of a Tool for Assessing Clinical Competence of Master Science Nurse Students. Journal of Biology, Agriculture and Healthcare, 3(3), 53-63.

5. Couto, C. B. D., \& Teresinha, M. D. S. G. (2012). The nursing process according to the international classification for nursing practice: an integrative review. Text Context Nursing, 21(2), 440-447.

6. De La Cuesta, C. (1983). The nursing process: from development to implementation. Journal of Advanced Nursing, 8, 365-371.

7. Dépelteau, F. (2000). La démarche d'une recherche en sciences humaines. Bruxelles: Presses de l'Université de Laval.

8. Edelman, C., \& Mandle, C. (2002). Health promotion throughout the lifespan $\left(5^{\text {th }} \mathrm{ed}.\right)$. Mosby: St. Louis.

9. Elliott, D. D. (1996). Promoting Critical Thinking in the Classroom. Nurse Educator, 21(2), 49-52. doi: 10.1097/00006223-199603000-00015

10. Eyinga, P. M. (2010). Obstacles à l'autonomie de la profession infirmière dans les hôpitaux de première catégorie de Yaoundé. (Unpublished Master Thesis). Catholic University of Central Africa, Yaoundé.

11. Johnson, D. E. (1959). A philosophy of nursing. Nursing Outlook, 7(4), 198-200.

12. Jun-Yan, S., Xiu-Li, Z., Cui-Ping, L., Xiu-Xin, M., Xue-Zhu, L., Hui-Li, G., \& Chi, T. (2015). Comparison of clinical thinking ability in nursing students of different grades. Chinese Nursing Research, 1, 1-4.

13. Kaddoura, M. A. (2011). Critical Thinking Skills of Nursing Students in Lecture-Based Teaching and Case-Based Learning. International Journal for the Scholarship of Teaching and Learning (5)2.doi:10.20429/ijsotl.2011.050220

14. Kak, N., Burkhalter, B., \& Cooper, M-A. (2001). Measuring the Competence of Healthcare
Providers. Operations Research Issue Paper, 2(1), 1-23.

15. Kermansaravi, F., Navidian, A., \& Kaykhaei, A. (2013). Critical Thinking Dispositions Among Junior, Senior and Graduate Nursing Students in Iran. Procedia-Social and Behavioral Sciences, 83, 574-579.

16. Kurfiss, J. G. (1988). Critical thinking: theory, research, practice, and possibilities. Washington DC: Association for the Study of Higher Education.

17. Mahmoud, A. S., \& Mohamed, H. A. (2017). Critical thinking dispositions among nurses working in public hospitals at Port-said Governorate. International Journal of Nursing Sciences, 4(2), 128-134.

18. Rush, S., Fergy, S., Wells, D. (1996). Professional development. Care planning: knowledge for practice (continuing education credit).Nursing Times, 92(36), 1-4.

19. Wiedenbach, E. (1963). The helping art of nursing. American Journal of Nursing, 63(11), 54-57.

20. Yura, H., \& Walsh, M. (1967). The Nursing Process: Assessing, Planning, Implementing, Evaluating. Norwalk, CT: Appleton Century Crofts.

\section{5}

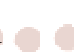

